\title{
Mentored peer review of standardized manuscripts as a teaching tool for residents: a pilot randomized controlled multi-center study
}

Victoria S. S. Wong ${ }^{1,11^{*}}$, Roy E. Strowd III2, Rebeca Aragón-García ${ }^{3}$, Yeseon Park Moon ${ }^{3}$, Blair Ford ${ }^{3}$, Sheryl R. Haut ${ }^{4}$, Joseph S. Kass ${ }^{5}$, Zachary N. London ${ }^{6}$, MaryAnn Mays ${ }^{7}$, Tracey A. Milligan ${ }^{8}$, Raymond S. Price ${ }^{9}$, Patrick S. Reynolds ${ }^{2}$, Linda M. Selwa ${ }^{6}$, David C. Spencer ${ }^{1}$ and Mitchell S. V. Elkind $d^{3,10}$

\begin{abstract}
Background: There is increasing need for peer reviewers as the scientific literature grows. Formal education in biostatistics and research methodology during residency training is lacking. In this pilot study, we addressed these issues by evaluating a novel method of teaching residents about biostatistics and research methodology using peer review of standardized manuscripts. We hypothesized that mentored peer review would improve resident knowledge and perception of these concepts more than non-mentored peer review, while improving review quality.

Methods: A partially blinded, randomized, controlled multi-center study was performed. Seventy-eight neurology residents from nine US neurology programs were randomized to receive mentoring from a local faculty member or not. Within a year, residents reviewed a baseline manuscript and four subsequent manuscripts, all with introduced errors designed to teach fundamental review concepts. In the mentored group, mentors discussed completed reviews with residents. Primary outcome measure was change in knowledge score between pre- and post-tests, measuring epidemiology and biostatistics knowledge. Secondary outcome measures included level of confidence in the use and interpretation of statistical concepts before and after intervention, and RQI score for baseline and final manuscripts.

Results: Sixty-four residents (82\%) completed initial review with gradual decline in completion on subsequent reviews. Change in primary outcome, the difference between pre- and post-test knowledge scores, did not differ between mentored $(-8.5 \%)$ and non-mentored $(-13.9 \%)$ residents $(p=0.48)$. Significant differences in secondary outcomes (using 5-point Likert scale, $5=$ strongly agree) included mentored residents reporting enhanced understanding of research methodology (3.69 vs 2.61; $p=0.001$ ), understanding of manuscripts (3.73 vs 2.87; $p=0.006$ ), and application of study results to clinical practice (3.65 vs $2.78 ; p=0.005)$ compared to non-mentored residents. There was no difference between groups in level of interest in peer review (3.00 vs $3.09 ; p=0.72)$ or the quality of manuscript review assessed by the Review Quality Instrument (RQI) (3.25 vs 3.06; $p=0.50$ ). (Continued on next page)
\end{abstract}

\footnotetext{
* Correspondence: vwongmd@gmail.com

'Department of Neurology, Oregon Health and Science University, Portland, OR, USA

${ }^{11}$ The Queens Medical Center Neuroscience Institute, 1301 Punchbowl St., QET5, Honolulu, HI 96813, USA

Full list of author information is available at the end of the article
} 
(Continued from previous page)

Conclusions: We used mentored peer review of standardized manuscripts to teach biostatistics and research methodology and introduce the peer review process to residents. Though knowledge level did not change, mentored residents had enhanced perception in their abilities to understand research methodology and manuscripts and apply study results to clinical practice.

Keywords: Peer review, Training, Education, Medical residency

\section{Background}

With an ever-expanding body of scientific literature [1] and peer reviewers in demand [2], there is a need to train potential peer reviewers to keep up with the growing need. Simultaneously, there is a continued emphasis from the Accreditation Council for Graduate Medical Education (ACGME) to train residents to appraise and assimilate scientific evidence from the biomedical literature [3]. Prior studies have found that formal education in biostatistics and research methodology during residency is lacking [47]. By training residents in the peer review process, there is potential to develop a larger pool of peer reviewers while providing them with the skills necessary to interpret and produce scholarly works that impact patient care.

In this current pilot study, we evaluated a novel method of teaching neurology residents the basic concepts of biostatistics, research methodology, and review of scholarly literature employing a program of peer review of scientific manuscripts. We hypothesized that mentored peer review of standardized manuscripts is feasible and would improve resident perception and knowledge of the principles of biostatistics and research methodology more than nonmentored peer review.

\section{Methods}

\section{Study sites and population}

A partially blinded, randomized, controlled multi-center pilot study of mentored peer review of standardized manuscripts was performed. Through the American Academy of Neurology (AAN) Consortium of Neurology Program Directors, we sent an e-mail invitation to Program Directors of ACGME-accredited adult neurology residency programs in the USA to participate. Participation interest was high with 38 sites expressing preliminary interest. Nine sites were chosen based on the size of residency program (to maximize the number of resident participants) and the sites at which study investigators were affiliated. Study sites included the Montefiore Medical Center, Albert Einstein College of Medicine; Baylor College of Medicine; Brigham and Women's Hospital and Massachusetts General Hospital (Partners); Cleveland Clinic; Columbia University; Oregon Health \& Science University; University of Michigan; University of Pennsylvania; and Wake Forest Baptist Medical Center. We recruited adult neurology residents in their post- graduate years (PGY) 3 and 4 from the nine chosen study sites. Volunteer mentors were recruited locally from existing faculty at each site. An outline of the curriculum and brief guidelines were provided to each faculty mentor. The curriculum outline is available in an additional file (see Additional file 1).

\section{Human subject protection}

The institutional review boards at each participating study site either approved or exempted the research protocol as an education research study, based on local regulations and criteria. All resident participants provided written informed consent as required by their study site.

\section{Study design}

Program directors received an introductory packet including study overview and the brief curriculum mentioned above. Program directors and coordinators were instrumental in study coordination and facilitating preand post-test administration. All consenting neurology resident participants took an initial pre-test assessing knowledge of biostatistics and research methodology (see "Survey instruments and knowledge tests" below). Prior to receiving any manuscripts for review, all residents received a document with basic tips on effective peer review. They were also each given the reference textbook Clinical Epidemiology: The Essentials [8].

\section{Blinding and allocation concealment}

Residents were randomized (1:1) to mentored and nonmentored groups within each site by a research assistant who used a computerized random number generator to perform the group allocation.

\section{Intervention}

Each mentored resident had one mentor. Residents were given a baseline standardized manuscript (manuscript 1) for peer review (see "Standardized manuscripts" below) to serve as a baseline (Fig. 1). Their randomization status (mentored vs non-mentored) was revealed to them after completion of the first review. Mentors were advised to discuss the reviews with residents after completion of each manuscript review, focusing on key teaching points outlined in the program curriculum for 


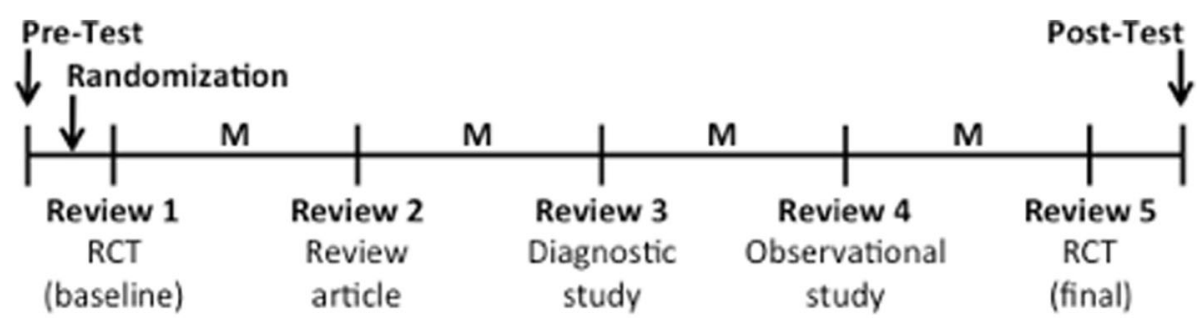

Fig. 1 Study schema. Abbreviations: M mentor meeting (for those randomized to the mentored group), $R C T$ randomized controlled trial

each manuscript. For the mentored group, meetings with the mentor were mandatory after completion of each of the first four manuscripts, though compliance was not enforced. Residents in the non-mentored group were not assigned a faculty mentor but continued to receive manuscripts and were expected to complete reviews.

Including the baseline manuscript (manuscript 1), residents were given a total of five manuscripts for review at two-month intervals, with the study period lasting from 2012 to 2013. Each resident participant as well as the faculty mentors received the same sets of standardized manuscripts. Residents had a 6-week period to complete the manuscript review and meet with their mentor, if applicable. There was a 2-week grace period per review period, and late reviews were accepted.

\section{Standardized manuscripts}

The five standardized manuscripts incorporated deliberate errors, using a previously published methodology [9]. Manuscripts from 2004 to 2007 were chosen, with permission from the Neurology ${ }^{\circ}$ journal, to minimize the chance that residents would have read these articles while in training [10-14]. Manuscripts were chosen to represent different experimental designs, including randomized controlled trials (manuscripts 1 and 5, allowing for comparison of review quality) [10, 11], a review (manuscript 2) [12], a diagnostic accuracy study (manuscript 3) [13], and an observational study (manuscript 4) [14].

Ten deliberate errors per manuscript were introduced to adhere to a standardized curriculum of topics related to biostatistics, and research methodology after permission was obtained from the corresponding authors. The entire list of introduced manuscript errors is available as a separate file (see Additional file 2). Deliberate subversion of reporting guidelines including CONSORT [15], PRISMA [16], STARD [17], and STROBE [18] was performed to create these deliberate errors.

\section{Survey instruments and knowledge tests}

Demographic and educational history data, including experiences likely to influence review quality and knowledge, were collected at enrollment (e.g., age, sex, primary academic degree[s], other degrees, research experience, peer reviewing experience, location of residency, prior training in research methods, and prior training in evidence-based medicine). Pre-test and post-test questions reflecting knowledge of epidemiology and biostatistics were obtained from two published studies $[5,6]$. Each test contained 20 questions, without repetition of questions.

Residents' perception of their understanding of biostatistics, level of confidence about use and interpretation of statistical concepts, and application of scientific study results to patient care were also assessed on a 5-point Likert scale ( $1=$ strongly disagree to $5=$ strongly agree) at baseline and study end. Residents were also asked to provide reasons for difficulty completing reviews and to evaluate their experience in the study.

\section{Evaluation of peer review quality}

The quality of manuscript reviews was measured with the Review Quality Instrument (RQI), a validated instrument used to measure the quality of peer reviews in prior studies [19]. The RQI assesses whether reviews cover major important points in a research article using a 5-point Likert scale, including importance of the research question, originality, strengths and weaknesses, and interpretation. It also assesses whether the reviewer made comments on organization and writing, referenced examples within the paper, and provided constructive criticism. The first seven questions of the RQI encompass each of these points, while the eighth question assesses the overall review quality.

The RQI was used by two of the study authors (VSSW, MSVE) to assess review quality of manuscript 1 (baseline measure) and manuscript 5 (post-intervention assessment); study authors were blinded to group and identity.

\section{Outcome measures}

The primary outcome measure was the change in knowledge between the pre-test and the post-test performed after review of all manuscripts. Secondary outcome measures included level of confidence in the use and interpretation of statistical concepts before and after the intervention, as well as the RQI score for the baseline (manuscript 1) and final (manuscript 5) manuscripts. Both 
manuscript 1 and manuscript 5 were randomized controlled trials, allowing for comparison of review quality.

\section{Statistical analysis}

Demographics and educational experiences at enrollment were compared using chi-square tests for categorical measures and Wilcoxon rank-sum tests for continuous measures. Results were summarized as means ( \pm standard deviation) and proportions (\%) as appropriate. Primary and secondary outcome measure scores were compared using ANCOVA or Wilcoxon rank-sum tests as appropriate for the two groups (with and without mentorship). For the primary outcome of the change in knowledge based on pre- and post-test scores, the change was calculated only among those with both tests completed and compared accounting for pre-test scores. We also tested whether pre-test score was dependent on missing the post-test using logistic regression with indication of missingness ( 1 for post-test not done and 0 for post-test done) as a dependent variable and pre-test as an independent variable. For other outcomes, we analyzed all available data. The average score of two reviewers was used for the RQI outcome. The inter-rater reliability of the RQI between the two reviewers was tested using the intra-rater correlation coefficient (ICC). Software used for analysis was SAS version 9.3 (SAS Institute, Cary, NC).

\section{Results}

A total of 78 residents from 9 neurology programs were enrolled and randomized to the mentored ( $n=39,50 \%)$ and non-mentored $(n=39,50 \%)$ groups. Fourteen residents withdrew from the study, 5 mentored and 9 non- mentored (Fig. 2). Baseline characteristics were similar between groups, though time from medical school was slightly longer in the non-mentored group (Table 1). Both mentored and non-mentored residents were likely to report previously having a mentor (79 and 95\%, respectively), with a trend toward more baseline mentoring in the non-mentored group (Table 1). Approximately half of the participants reported receiving prior teaching in epidemiology $(n=35,45 \%)$, biostatistics $(n=38,49 \%)$, or evidence-based medicine $(n=48,62 \%)$. The majority of residents reported reading scientific journals $(n=76,97 \%)$ and participating in prior research $(n=67,86 \%)$.

Baseline perceptions of level of knowledge and confidence in biostatistics were well matched between groups (Table 1). Residents strongly agreed that they would like to learn more about biostatistics and that it was necessary to know about statistics to intelligently interpret the medical literature. Confidence in understanding statistical terms, interpreting $p$ values, interpreting statistical methods, assessing whether the correct statistical procedure was used in a study, identifying factors influencing study power, and applying study results to clinical practice were all low and not statistically different between groups (all $p>0.40$ ).

Participation was high initially with 64 (82\%) residents completing review of manuscript 1 ; there was a gradual decline over time (49 [63\%] completed review of manuscript 2, 35 [45\%] completed manuscript 3, 29 [42\%] completed manuscript 4, and 44 [56\%] completed manuscript 5 ; Table $2(\mathrm{~A}))$. The investigators strongly encouraged residents to complete manuscript 5 . The majority of residents ( $n=46,59 \%$ ) completed at least 3 of 5 manuscript reviews.

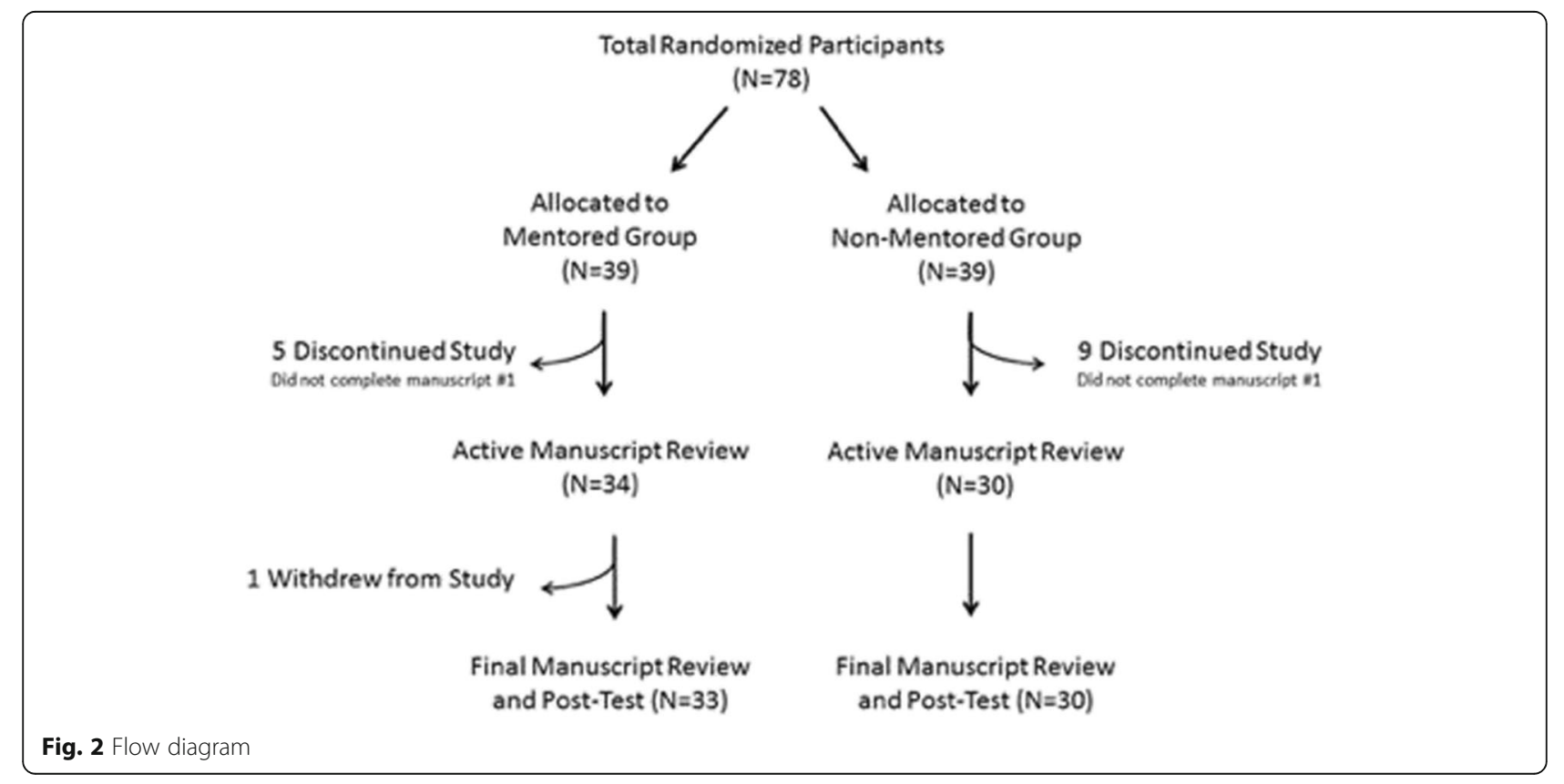


Table 1 Participant characteristics

\begin{tabular}{|c|c|c|c|}
\hline Demographics $(n)$ & Total (78) & Non-mentored (39) & Mentored (39) \\
\hline Age, years, mean (STD) & $30.8(2.6)$ & $30.2(2.2)$ & $31.3(2.8)$ \\
\hline Male sex, $n(\%)$ & $39(50 \%)$ & $21(54 \%)$ & $18(46 \%)$ \\
\hline \multicolumn{4}{|l|}{ Advanced degrees, $n$ (\%) } \\
\hline$-M D$ & $57(73 \%)$ & $28(72 \%)$ & $29(74 \%)$ \\
\hline$-\mathrm{DO}$ & $2(3 \%)$ & $1(3 \%)$ & $1(3 \%)$ \\
\hline - Additional Graduate degree & $18(23 \%)$ & $10(25.6 \%)$ & $9(23 \%)$ \\
\hline Years since medical school, mean (STD) & $3.4(1.7)$ & $3.7(2.0)$ & $3.1(1.3)$ \\
\hline \multicolumn{4}{|l|}{ Year in training, $n(\%)$} \\
\hline - PGY3 & $37(47 \%)$ & $22(56 \%)$ & $15(38 \%)$ \\
\hline$-P G Y 4^{a}$ & $41(53 \%)$ & $17(44 \%)$ & $24(62 \%)$ \\
\hline Prior epidemiology education, $n(\%)$ & $35(45 \%)$ & $16(41 \%)$ & $19(49 \%)$ \\
\hline Prior biostatistics education, $n(\%)$ & $38(49 \%)$ & $21(54 \%)$ & $17(44 \%)$ \\
\hline Prior evidence-based medicine education, $n(\%)$ & $48(62 \%)$ & $27(69 \%)$ & $21(54 \%)$ \\
\hline Reads scientific journals, $n$ (\%) & $76(97 \%)$ & $38(97 \%)$ & $38(97 \%)$ \\
\hline Participated in research, $n$ (\%) & $67(86 \%)$ & $33(85 \%)$ & $34(87 \%)$ \\
\hline \multicolumn{4}{|l|}{ No. prior publications, $n(\%)$} \\
\hline-0 & $32(41 \%)$ & $16(41 \%)$ & $16(41 \%)$ \\
\hline$-1-5$ & $39(50 \%)$ & $19(49 \%)$ & $20(51 \%)$ \\
\hline$->5$ & 7 (9\%) & $4(10 \%)$ & $3(8 \%)$ \\
\hline Current faculty mentor, $n(\%)$ & $68(87 \%)$ & 37 (95\%) & 31 (79\%) \\
\hline \multicolumn{4}{|c|}{ Baseline perceptions of biostatistics: 5 -point Likert score ( 1 = strongly disagree to $5=$ strongly agree) } \\
\hline "Would like to learn more about biostatistics," mean (STD) & $4.38(0.84)$ & $4.44(0.85)$ & $4.33(0.84)$ \\
\hline "Can understand almost all of statistical terms in journal articles," mean (STD) & $2.68(0.93)$ & $2.64(0.99)$ & $2.72(0.89)$ \\
\hline "I do not trust statistics," mean (STD) & $2.4(0.87)$ & $2.54(0.82)$ & $2.34(0.91)$ \\
\hline "I use statistical information in medical care," mean (STD) & $3.54(0.94)$ & $3.49(0.91)$ & $3.59(0.97)$ \\
\hline "Necessary to know about statistics," mean (STD) & $4.71(0.54)$ & $4.64(0.63)$ & $4.77(0.43)$ \\
\hline \multicolumn{4}{|l|}{ Confidence in ability to, mean (STD) } \\
\hline - Interpret $p$ values & $3.73(0.82)$ & $3.82(0.76)$ & $3.64(0.87)$ \\
\hline - Interpret statistical methods & $2.71(0.69)$ & $2.74(0.75)$ & $2.67(0.62)$ \\
\hline - Assess if correct statistical procedure used & $1.96(0.81)$ & $1.95(0.76)$ & $1.97(0.87)$ \\
\hline - Identify factors influencing study power & $2.45(0.77)$ & $2.41(0.88)$ & $2.49(0.64)$ \\
\hline - Apply study results to clinical practice & $2.96(0.69)$ & $2.97(0.67)$ & $2.95(0.7)$ \\
\hline
\end{tabular}

Abbreviation: STD standard deviation

${ }^{a}$ Includes 1 PGY-5 in pediatric neurology

There was no difference between groups in the overall number of reviews completed (Table 2 (B)). The most frequently reported impediment to manuscript review was the residents' busy schedules, with $65 \%(n=30)$ reporting this as the primary reason for not completing a manuscript review.

Twenty-five of the 39 residents (64\%) who were randomized to the mentored group responded to the post-intervention questions on the frequency of mentor meetings. The 25 who responded reported a mean of $2.8 \pm 1.2$ out of 4 expected mentor-mentee meetings and a median of 3 meetings. Five (20\%) completed one meeting, 5 (20\%) completed two meetings, 6 (24\%) completed three meetings, 8 (32\%) completed four meetings, and $1(4 \%)$ completed five meetings (though we did not request a meeting after the final manuscript review). Fifteen $(60 \%)$ completed three or more mentor meetings.

Several barriers to meeting with mentors were expressed, but the most often cited $(n=12,71 \%)$ was the busy resident schedule. An additional table reporting barriers to review completion and mentor meetings, as well as desire for mentorship is available in a separate file (see Additional file 3). Overall, residents indicated a strong interest in being mentored, with $82 \%(n=40)$ 
Table 2 Reviews completed by all enrolled participants

\begin{tabular}{|c|c|c|c|c|}
\hline Part A: specific manuscript reviews completed & Total, $n=78$ & Non-mentored, $n=39$ & Mentored, $n=39$ & \\
\hline Manuscript 1: randomized controlled trial & $64(82 \%)$ & $30(47 \%)$ & $34(53 \%)$ & \\
\hline Manuscript 2: systematic review & $49(63 \%)$ & $26(53 \%)$ & $23(47 \%)$ & \\
\hline Manuscript 3: diagnostic accuracy study & $35(45 \%)$ & $18(51 \%)$ & $17(49 \%)$ & \\
\hline Manuscript $4^{\mathrm{a}}$ : observational study & $29(42 \%)$ & $14(48 \%)$ & $15(52 \%)$ & \\
\hline Manuscript 5: randomized controlled trial & $44(56 \%)$ & $24(55 \%)$ & $20(45 \%)$ & \\
\hline Part B: total number of reviews completed & Total (\%) & Non-mentored & Mentored & $p$ value $^{\dagger}$ \\
\hline No reviews completed & $14(18.0)$ & $9(64 \%)$ & $5(36 \%)$ & 0.238 \\
\hline 1 review & $10(12.8)$ & $2(20 \%)$ & $8(80 \%)$ & 0.0421 \\
\hline 2 reviews & $8(10.3)$ & $4(50 \%)$ & $4(50 \%)$ & 1 \\
\hline 3 reviews & $10(12.8)$ & $5(50 \%)$ & $5(50 \%)$ & 1 \\
\hline 4 reviews & 15 (19.2) & $8(53 \%)$ & 7 (47\%) & 0.77 \\
\hline 5 reviews & $21(26.9)$ & 11 (52\%) & $10(48 \%)$ & 0.799 \\
\hline
\end{tabular}

${ }^{a} 9$ students (5 non-mentored, 4 mentored) only received 4 manuscripts and did not complete manuscript 4

${ }^{+}$Chi-squared with 1 degrees of freedom test

indicating that they would desire mentoring in future similar studies. Mentored residents were more likely to feel indifferent about the benefits of mentoring compared to non-mentored residents ( 24 vs $8 \%$ ).

\section{Primary outcome measure}

Pre-test knowledge scores were $66.0 \pm 14.7 \%$ correct, and post-test scores were $54.9 \pm 12.1 \%$ correct (Table 3 (A)). Seventy-eight residents took the initial pre-test, of whom 51 completed the post-test. Pre-test scores did not differ between those with both test done vs. only pre-test done $(p=0.85)$. Scores trended similarly in mentored and non-mentored residents and were not different at follow-up $(p=0.14)$. The mentored group had less decline in the change between pre-test and post-test compared to the non-mentored group, though no significant difference was found $(p=0.48)$.

\section{Secondary outcome measures}

After intervention, mentored residents perceived enhanced experiences compared to non-mentored residents in several topics, including understanding research methodology $(p=$ $0.001)$, understanding of manuscripts $(p=0.006)$, application of study results to clinical practice $(p=0.005)$, and explanation of studies to patients $(p=0.010)$. No difference was observed between groups in the overall perception of the quality of their experience in the program (Table 3 (B)).

The inter-rater reliability of the RQI was good (ICC $=0.7$ for the two independent reviewers). The quality of manuscript review as assessed by the RQI did not differ between groups (Table $3(\mathrm{C})$ ).

\section{Discussion}

This pilot study demonstrates the use of an innovative approach to teaching peer review. Mentoring did not impact either the quality of peer review or knowledge of biostatistics, though it impacted perceived knowledge and confidence in understanding of research methodology, scientific manuscripts, and application of scientific data to clinical practice and patient care.

Peer review quality was assessed in this study using the RQI. No difference in review quality was found between the baseline and final manuscript review. Numerous prior attempts at training peer reviewers, including the use of training workshops $[9,20,21]$, self-taught training packages [9], and written feedback from journal editors [22], have not yielded sustained improvements in peer review quality. To our knowledge, this is the first study using the RQI to evaluate review quality in a trainee population (i.e., residents). Further studies will be needed to test whether more structured approaches to mentoring, training of mentors, or supplementing with a formal curriculum on biostatistics for residents can improve peer review quality.

Residency training is an important time to teach, develop, and reinforce skills in critical appraisal of medical literature and implementation of scientific data to patient care. Numerous curricula have been explored to teach the important principles underlying biostatistics, research methodology, and evidence-based medicine [23, 24]. Our novel approach integrates clinically relevant studies which impact neurologic patient care with an exposure to peer review of manuscripts. Curricula of this type which include formal training in peer review are lacking [25].

The impact of mentoring in this study was uncertain. The role of mentorship in promoting career advancement, increasing scholarly activities, encouraging professionalism, enhancing personal growth, and improving career satisfaction is well recognized [26-28]. However, in our 
Table 3 Knowledge, Review Quality Instrument, and study perception

\begin{tabular}{|c|c|c|c|c|}
\hline & Total & Non-mentored & Mentored & $p$ value \\
\hline \multicolumn{5}{|l|}{ Part A: knowledge questions } \\
\hline Pre-test, mean \% correct (STD), $n$ & $66.0(14.7), n=51$ & $67.8(14.2), n=25$ & $64.2(15.3), n=26$ & 0.65 \\
\hline Post-test, mean \% correct (STD), $n$ & $54.9(12.1), n=51$ & $53.9(11.8), n=25$ & $55.8(12.3), n=26$ & $0.14^{* *}$ \\
\hline Change in score, \% decline (STD), $n$ & $-11.1(17.5), n=51$ & $-13.9(16.7), n=25$ & $-8.5(18.2), n=26$ & $0.48^{* *}$ \\
\hline \multicolumn{5}{|c|}{ Part B: overall study perception, 5 -point Likert score from $1=$ strongly disagree to $5=$ strongly agree (STD) } \\
\hline \multicolumn{5}{|l|}{ Participation has enhanced: } \\
\hline - Understanding of research methodology & $3.18(1.1)$ & $2.61(1.2)$ & $3.69(0.8)$ & 0.001 \\
\hline - Interest in clinical research & $3.08(1.1)$ & $2.83(1.2)$ & $3.31(1.0)$ & 0.108 \\
\hline - Understanding of manuscripts & $3.33(1.1)$ & $2.87(1.3)$ & $3.73(0.9)$ & 0.006 \\
\hline - Motivation to read more manuscripts & $3.12(1.1)$ & $2.78(1.2)$ & $3.42(0.9)$ & 0.075 \\
\hline - Interest in peer review & $3.04(1.0)$ & $3.09(0.9)$ & $3.00(1.1)$ & 0.72 \\
\hline - Interest in academic neurology & $3.00(1.0)$ & $2.83(1.0)$ & $3.15(1.1)$ & 0.375 \\
\hline - Application of study results to clinical practice & $3.25(1.1)$ & $2.78(1.1)$ & $3.65(0.9)$ & 0.005 \\
\hline - Explanation of studies to patients & $2.90(1.2)$ & $2.43(1.3)$ & $3.31(0.9)$ & 0.010 \\
\hline - Overall impression & $3.39(1.1)$ & $3.22(1.1)$ & $3.54(1.0)$ & 0.279 \\
\hline - Enjoyment in participating in research study & $3.18(1.1)$ & $3.17(1.1)$ & $3.19(1.1)$ & 0.925 \\
\hline \multicolumn{5}{|l|}{ Part C: RQI scores } \\
\hline \multicolumn{5}{|l|}{ Manuscript 1, mean (STD) } \\
\hline - Mean of Q1-7 & $3.46(0.8)$ & $3.38(0.9)$ & $3.53(0.7)$ & 0.56 \\
\hline - Mean of Q8 & $3.48(0.9)$ & $3.45(1.1)$ & $3.51(0.8)$ & 0.92 \\
\hline \multicolumn{5}{|l|}{ Manuscript 5, mean (STD) } \\
\hline - Mean of Q1-7 & $3.15(0.84)$ & $3.06(0.97)$ & $3.25(0.7)$ & 0.50 \\
\hline - Mean of Q8 & $3.31(1.0)$ & $3.13(1.1)$ & $3.53(0.8)$ & 0.19 \\
\hline
\end{tabular}

Abbreviations: STD standard deviation, $R Q /$ Review Quality Index, $Q$ question

"Wilcoxon rank-sum test

*ANCOVA adjusting for pre-test scores

current study, mentoring did not appear to impact knowledge acquisition or performance. Potential explanations include the high prevalence of faculty mentoring and reading of scientific articles at baseline, as well as the trend toward higher baseline mentoring in the nonmentored group. While a general curriculum outlining goals and pertinent topics as well as an introductory epidemiology and biostatistics text was provided to each program involved in the study, formal training for mentors and a structured resident curriculum was not incorporated into our pilot study and could be considered in future studies, particularly given evidence from other studies on the positive impact of mentor training on mentoring quality [29].

Our data provide evidence that there may be positive and negative aspects to mentorship. Qualitative comments provided by participants suggested that residents in the non-mentored group expressed disappointment about not being assigned a mentor. However, residents in the mentored group were no more likely to have completed manuscript reviews compared to the non- mentored group. For those residents who were assigned a mentor, obstacles to meeting with the mentor did exist and difficulties in finding time to meet may have led residents in the mentored group to forgo review completion altogether if they felt that they would not be able to arrange a meeting.

Our study has limitations. Formal training for volunteer faculty mentors was not included and, while a curriculum of suggested topics was provided, instruction provided to each resident was not standardized. There is also an inevitable variability in mentorship quality and style, as well as variation in number of mentors across sites. Participating residents had high baseline rates of reading of scientific journals and mentorship, possibly reducing the effect size of the intervention. Mentor-mentee meetings were mandated, but compliance was not enforced, potentially diluting an effect of the study intervention. The time given to complete each manuscript may have been insufficient, resulting in reduced completion rates mid-way through the study. This mirrors real world peer review limitations, with time constraints sited as the primary reason for 
refusing to complete peer reviews [30]. Lastly, the sample size was small in this pilot study focusing only on neurology residents, and future consideration should be made to a wider scale study including trainees in other specialties, allowing for a greater degree of generalization.

Our study also had strengths. We incorporated a novel hands-on teaching tool in a multi-center study to address a known knowledge gap in residency training. The use of standardized manuscripts representing different study designs with systematically introduced errors provided a broad scope of teaching points, so that the residents could learn more about different aspects of biostatistics and research methodology. Additional long-term follow-up data on the impact of this novel educational design on future resident scholarship are ongoing. Future directions to improve the benefit of using peer review as a teaching tool include increased guidance of faculty mentors, use of more specialized but remote mentors [31] (e.g., established editors of scientific journals with an interest in peer review), focus on a more formal curriculum, web-based tutorials, fewer manuscript assignments, and the potential use of live submitted manuscripts rather than standardized ones to provide a more realistic review experience. These changes may pique resident interest and encourage continued participation.

\section{Conclusions}

In conclusion, we used mentored peer review of standardized manuscripts to introduce the concept of peer review and to teach the principles of biostatistics and research methodology to neurology residents. Although primary outcome measure of content knowledge did not increase, mentored residents had an enhanced perception in their abilities to understand research methodology and scientific manuscripts as well as their ability to apply study results to clinical practice and explain these to patients. Future studies with a larger sample size, incorporating formal mentoring training and a more detailed curriculum, may enhance the impact of this education intervention and its application to both the peer review process and patient care.

\section{Additional files}

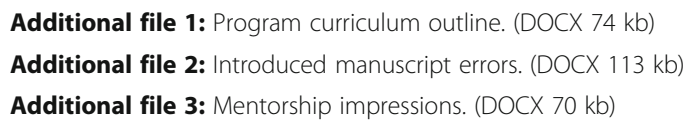

\section{Acknowledgements}

The authors wish to thank Kathy Pieper, Sandi Moriarity, and the volunteer faculty mentors.

\section{Funding}

This study was supported by an Education Research Grant from the American Academy of Neurology Institute.

\section{Availability of data and materials}

The datasets generated and analyzed during the current study are not publicly available due to lack of a public central repository but are available from the corresponding author on reasonable request.

\section{Authors' contributions}

WW, RS, RA, YM, LS, and ME made substantial contributions to the conception and design as well as the analysis and interpretation of data. WW, $R S, R A, B F, S H, J K, Z L, M M, T M, R P, P R$, DS, and ME made substantial contributions to acquisition of data. WW, RS, RA, YM, and ME have been involved in drafting the manuscript. BF, SH, JK, ZL, MM, TM, RP, PR, LS, and DS have been involved in revising the manuscript critically for important intellectual content. All authors have given final approval of the version to be published, have participated sufficiently in the work to take public responsibility for appropriate portions of the content, and agree to be accountable for all aspects of the work in ensuring that questions related to the accuracy or integrity of any part of the work are appropriately investigated and resolved.

\section{Competing interests}

Dr. Wong serves on the editorial board of Research Integrity and Peer Review. Dr. Strowd reports no disclosures. Ms. Aragón-García reports no disclosures. Ms. Moon reports no disclosures. Dr. Ford reports no disclosures. Dr. Haut has served as a consultant and on the DSMB for Acorda. Dr. Kass reports no disclosures. Dr. London reports no disclosures. Dr. Mays has received personal compensation as a speaker for Allergan. Dr. Milligan reports no disclosures. Dr. Price reports no disclosures. Dr. Reynolds reports no disclosures. Dr. Selwa reports no disclosures. Dr. Spencer reports no disclosures. Dr. Elkind receives personal compensation from the American Academy of Neurology (AAN) for serving as the Associate Editor of the Resident and Fellow Section, and for providing educational lectures at AAN-sponsored CME conferences. Dr. Elkind also receives compensation for providing consultative services for Biogen IDEC, BioTelemetry, BMS-Pfizer Partnership, Boehringer-Ingelheim, Daiichi-Sankyo, and Janssen Pharmaceuticals; receives research support from diaDexus, Inc. and the NIH/NINDS (R01 NS48134, R01 NS50724, R37 NS29993, NINDS P50 NS49060, R01 NS55809, R01 NS62820); has given expert legal opinions on behalf of Merck/Organon (NuvaRing ${ }^{\oplus}$ and stroke litigation); and serves on the National, Founders Affiliate, and New York City chapter boards of the American Heart Association/American Stroke Association. He receives royalties from UpToDate for chapters related to stroke.

\section{Consent for publication}

Not applicable.

\section{Ethics approval and consent to participate}

The institutional review boards at each participating study site either approved or exempted the research protocol as an education research study, based on local regulations and criteria. All resident participants provided written informed consent as required by their study site.

\section{Publisher's Note}

Springer Nature remains neutral with regard to jurisdictional claims in published maps and institutional affiliations.

\section{Author details}

'Department of Neurology, Oregon Health and Science University, Portland, OR, USA. ${ }^{2}$ Department of Neurology, Wake Forest Baptist Medical Center, 1 Medical Center Blvd, Winston-Salem, NC 27157, USA. ${ }^{3}$ Department of Neurology, Columbia University College of Physicians and Surgeons, 630 W 168th St, New York, NY 10032, USA. ${ }^{4}$ Department of Neurology, Montefiore Medical Center, Albert Einstein College of Medicine, 1300 Morris Park Avenue, Bronx, NY 10461, USA. ${ }^{5}$ Department of Neurology, Baylor College of Medicine, 1 Baylor Plaza, Houston, TX 77030, USA. ${ }^{6}$ Department of Neurology, University of Michigan, 500 S State St, Ann Arbor, MI 48109, USA. ${ }^{7}$ Department of Neurology, Cleveland Clinic, 9500 Euclid Avenue, Cleveland, $\mathrm{OH} 44195$, USA. ${ }^{8}$ Department of Neurology, Brigham and Women's Hospital, 75 Francis St, Boston, MA 02115, USA. ${ }^{9}$ Department of Neurology, University of Pennsylvania, 3400 Spruce St, Philadelphia, PA 19104, USA. ${ }^{10}$ Department of Epidemiology, Columbia University Mailman School of Public Health, 722 W 168th St, New York, NY 10032, USA. ${ }^{11}$ The Queens Medical Center Neuroscience Institute, 1301 Punchbowl St., QET5, Honolulu, HI 96813, USA. 
Received: 29 December 2016 Accepted: 2 May 2017

Published online: 05 June 2017

\section{References}

1. Key MEDLINE ${ }^{\oplus}$ Indicators. U.S. National Library of Medicine website. Available from: https://www.nlm.nih.gov/bsd/bsd_key.html. Accessed 19 Dec 2016.

2. Heinemann L. Reviewer: an endangered species?! J Diabetes Sci Technol. 2015:9(2):167-8.

3. Common Program Requirements. Accreditation Council for Graduate Medica Education website. Available from: http://www.acgme.org/What-We-Do/ Accreditation/Common-Program-Requirements. Accessed 10 May 2017.

4. Schuh LA, Adair JC, Drogan O, Kissela BM, Morgenlander JC, Corboy JR. Education research: neurology residency training in the new millennium. Neurology. 2009;72(4):e15-20

5. Windish DM, Huot SJ, Green ML. Medicine residents' understanding of the biostatistics and results in the medical literature. JAMA. 2007;298(9):1010-22.

6. Leira EC, Granner MA, Torner JC, Callison RC, Adams Jr HP. Education research: the challenge of incorporating formal research methodology training in a neurology residency. Neurology. 2008;70(20):e79-84.

7. West CP, Ficalora RD. Clinician attitudes toward biostatistics. Mayo Clin Proc 2007:82(8):939-43.

8. Fletcher R, Fletcher SW. Clinical epidemiology: the essentials. 4th ed. Philadelphia: Lippincott Williams \& Wilkins; 2005.

9. Schroter S, Black N, Evans S, Carpenter J, Godlee F, Smith R. Effects of training on quality of peer review: randomised controlled trial. BMJ. 2004; 328(7441):673.

10. Brooks BR, Thisted RA, Appel SH, Bradley WG, Olney RK, Berg JE, AVP923 ALS Study Group, et al. Treatment of pseudobulbar affect in ALS with dextromethorphan/quinidine: a randomized trial. Neurology. 2004; 63(8):1364-70.

11. Lipton RB, Göbel H, Einhäupl KM, Wilks K, Mauskop A. Petasites hybridus root (butterbur) is an effective preventive treatment for migraine. Neurology. 2004:63(12):2240-4.

12. Cronin S, Hardiman O, Traynor BJ. Ethnic variation in the incidence of ALS: a systematic review. Neurology. 2007;68(13):1002-7.

13. Jagust W, Reed B, Mungas D, Ellis W, Decarli C. What does fluorodeoxyglucose PET imaging add to a clinical diagnosis of dementia? Neurology. 2007;69(9):871-7.

14. Hankey GJ, Spiesser J, Hakimi Z, Bego G, Carita P, Gabriel S. Rate, degree, and predictors of recovery from disability following ischemic stroke. Neurology. 2007;68(19):1583-7.

15. Schulz KF, Altman DG, Moher D, for the CONSORT Group. CONSORT 2010 Statement: updated guidelines for reporting parallel group randomised trials. J Clin Epidemiol. 2010;63(8):834-40.

16. Moher D, Liberati A, Tetzlaff J, Altman DG, PRISMA Group. Preferred reporting items for systematic reviews and meta-analyses: the PRISMA statement. PLoS Med. 2009;6(7):e1000097.

17. Bossuyt PM, Reitsma JB, Bruns DE, Gatsonis CA, Glasziou PP, Irwig LM, et al. Standards for reporting of diagnostic accuracy. Towards complete and accurate reporting of studies of diagnostic accuracy: The STARD initiative. Ann Intern Med. 2003;138(1):40-4.

18. von Elm E, Altman DG, Egger M, Pocock SJ, Gøtzsche PC, Vandenbroucke JP, STROBE Initiative. The Strengthening the Reporting of Observational Studies in Epidemiology (STROBE) statement: guidelines for reporting observational studies. PLoS Med. 2007:4(10):e296.

19. van Rooyen S, Black N, Godlee F. Development of the review quality instrument (RQI) for assessing peer reviews of manuscripts. J Clin Epidemiol. 1999;52(7):625-9.

20. Callaham ML, Wears RL, Waeckerle JF. Effect of attendance at a training session on peer reviewer quality and performance. Ann Emerg Med. 1998;32(3 Pt 1):318-22.

21. Callaham ML, Schriger DL. Effect of structured workshop training on subsequent performance of journal peer reviewers. Ann Emerg Med. 2002;40(3):323-8.

22. Callaham ML, Knopp RK, Gallagher EJ. Effect of written feedback by editors on quality of reviews: two randomized trials. JAMA. 2002;287(21):2781-3.

23. Coomarasamy A, Khan KS. What is the evidence that postgraduate teaching in evidence based medicine changes anything? A systematic review. BMJ. 2004;329(7473):1017.

24. Windish DM. Brief curriculum to teach residents study design and biostatistics. Evid Based Med. 2011;16(4):100-4.
25. Kavic MS. Training surgery residents and fellows in the rigorous evaluation of academic literature. JSLS. 2014;18(2):165-6.

26. Frei E, Stamm M, Buddeberg-Fischer B. Mentoring programs for medical students - a review of the PubMed literature 2000-2008. BMC Med Educ. 2010;10:32.

27. Ramanan RA, Taylor WC, Davis RB, Phillips RS. Mentoring matters. Mentoring and career preparation in internal medicine residency training. J Gen Intern Med. 2006;21(4):340-5.

28. Straus SE, Sackett DL. Clinician-trialist rounds: 7. Mentoring: why every clinician-trialist needs to get mentored. Clin Trials. 2011;8(6):765-7.

29. Pfund C, House SC, Asquith P, Fleming MF, Buhr KA, Burnham EL, et al. Training mentors of clinical and translational research scholars: a randomized controlled trial. Acad Med. 2014;89(5):774-82.

30. Willis M. Why do peer reviewers decline to review manuscripts? A study of reviewer invitation responses. Learned Publishing. 2016:29:5-7.

31. Obura T, Brant WE, Miller F, Parboosingh IJ. Participating in a Community of Learners enhances resident perceptions of learning in an e-mentoring program: proof of concept. BMC Med Educ. 2011;11:13.

\section{Submit your next manuscript to BioMed Central and we will help you at every step:}

- We accept pre-submission inquiries

- Our selector tool helps you to find the most relevant journal

- We provide round the clock customer support

- Convenient online submission

- Thorough peer review

- Inclusion in PubMed and all major indexing services

- Maximum visibility for your research

Submit your manuscript at www.biomedcentral.com/submit 